\title{
Regulation of proline accumulation in detached rice leaves exposed to excess copper
}

\author{
Chien Teh Chen, Li-Men Chen, Chuan Chi Lin, Ching Huei Kao* \\ Department of Agronomy, National Taiwan University, Taipei, Taiwan, ROC
}

Received 24 April 2000; received in revised form 18 July 2000; accepted 15 September 2000

\begin{abstract}
Accumulation of proline in response to excess $\mathrm{Cu}$ was studied in detached leaves of rice (Oryza sativa). $\mathrm{CuSO}_{4}$ was effective in inducing proline accumulation in detached rice leaves under both light and dark conditions. $\mathrm{CuSO}_{4}$ and $\mathrm{CuCl}_{2}$ were equally effective in inducing proline accumulation, indicating that proline accumulation is induced by $\mathrm{Cu}$. Sulfate salts of $\mathrm{Mg}, \mathrm{Mn}$, and $\mathrm{Fe}$ were ineffective in inducing proline accumulation in detached rice leaves. Excess $\mathrm{Cu}$ had no effect on relative water content of detached rice leaves, suggesting that $\mathrm{Cu}$-induced proline accumulation is unlikely due to water deficit. Proline accumulation induced by excess $\mathrm{Cu}$ was related to proteolysis and an increase in $\Delta^{1}$-pyrroline-5-carboxylate reductase or ornithine- $\delta$-aminotransferase activity and could not be explained by proline utilization or stress-induced modifications in proline dehydrogenase or $\Delta^{1}$-pyrroline-5-carboxylate dehydrogenase. The content of glutamic acid decreased by excess $\mathrm{Cu}$. The increase in arginine but not ornithine was found to be associated with the increase in proline content in $\mathrm{Cu}$-stressed detached rice leaves. $\mathrm{CuSO}_{4}$ treatment resulted in an increase in abscisic acid content in detached rice leaves. The possibility that proline accumulation induced by excess $\mathrm{Cu}$ is mediated through abscisic acid is discussed. (c) 2001 Elsevier Science Ireland Ltd. All rights reserved.
\end{abstract}

Keywords: Abscisic acid; Copper; Oryza sativa; Proline accumulation

\section{Introduction}

Plants are exposed to various types of environmental stress. Among these stresses, osmotic stress, in particular that due to drought and salinity, is the most serious problem that limits plant growth and crop productivity in agriculture [1]. Proline accumulation in plant cells exposed to salt or water stress is a widespread phenomenon and is often considered to be involved in stress resistance

Abbreviations: ABA, abscisic acid; ELISA, enzyme-linked immunosorbent assay; FW, fresh weight; GABA, $\gamma$-aminobutyric acid; OAT, ornithine- $\delta$-aminotransferase; $\quad$ P5C,$\quad \Delta^{1}$-pyrroline-5-carboxylate; $\mathrm{P} 5 \mathrm{CDH}, \Delta^{1}$-pyrroline-5-carboxylate dehydrogenase; P5CR, $\Delta^{1}$-pyrroline-5-carboxylate reductase; $\mathrm{PDH}$, proline dehydrogenase; RWC, relative water content.

* Corresponding author. Tel.: +886-2-23698159; fax: + 886-223620879.

E-mail address: kaoch@ccms.ntu.edu.tw (C.H. Kao). mechanisms, although its precise role continues to be controversial [2-4].

Copper is an essential micronutrient for plants. Excess $\mathrm{Cu}$ induces a wide range of biochemical effects and physiological processes, such as photosynthesis, pigment synthesis, protein metabolism, and membrane integrity [5]. Based on the assumption that excess $\mathrm{Cu}$ can operate as one stress factor and may deteriorate the plant water balance [6], it is logical to expect that excess $\mathrm{Cu}$ may cause proline accumulation in plant tissues. In fact, excess $\mathrm{Cu}$-induced accumulation of proline has been reported in wheat seedlings [7], Lemna minor [8], Silene vulgaris [9], Anacystis [10] and Chlorella sp. [11,12].

Proline accumulation in plant tissues has been suggested to result from (a) a decrease in proline degradation; (b) an increase in proline biosynthe- 
sis; (c) a decrease in protein synthesis or proline utilization; and (d) hydrolysis of proteins [13]. In plants, proline is synthesized from glutamic acid via $\Delta^{1}$-pyrroline-5-carboxylate (P5C) by two enzymes, P5C synthetase and P5C reductase (P5CR). It has been shown from labelling experiments that ornithine can also serve as a precursor to proline biosynthesis in higher plants [14-16]. The isolation of cDNAs encoding ornithine- $\delta$-aminotransferase (OAT) in higher plants [17,18] suggests that the formation of P5C from ornithine. Arginine can also contribute to proline biosynthesis, and the pathway from arginine proceeds via ornithine as a result of catalytic activity of arginase [14,19]. Proline is metabolized to glutamic acid via P5C by two enzymes, proline dehydrogenase (PDH) and P5C dehydrogenase (P5CDH) [3]. Studying the effect of excess $\mathrm{Cu}$ on enzyme activities involved in proline biosynthesis and degradation could provide valuable information on the physiological significance of its accumulation. However, to our knowledge, no such study has been undertaken. Neither do we know whether three amino acids (glutamic acid, ornithine and arginine) involved in the proline biosynthetic pathways are limiting factors for proline accumulation induced by excess $\mathrm{Cu}$. In this paper, we shall examine the regulation of proline accumulation in detached rice leaves exposed to excess $\mathrm{Cu}$.

\section{Materials and methods}

\subsection{Plant material}

Rice (Oryza sativa cv. Taichung Native 1) was cultured as previously described [20]. The apical $3-\mathrm{cm}$ segments excised from the third leaves of 12-day-old seedlings were used. Briefly, rice seedlings were planted on a stainless net floating on half-strength Johnson's modified nutrient solution [21] in a $500 \mathrm{ml}$ beaker. The nutrient solution (pH 4.8) was replaced every 3 days. Rice plants were grown for 12 days in a greenhouse, where natural light was provided and the temperature was controlled at $30^{\circ} \mathrm{C}$ during the day and at $25^{\circ} \mathrm{C}$ at night. The apical $3 \mathrm{~cm}$ of the third leaf was used for the experiment. A group of ten segments was floated in a Petri dish containing $10 \mathrm{ml}$ of test solution. Incubation was carried out at $27^{\circ} \mathrm{C}$ in the light $\left(40 \mu \mathrm{mol} \mathrm{m}{ }^{-2} \mathrm{~s}^{-1}\right)$ or in the dark.
2.2. Determinations of proline, other amino acids, protein and chlorophyll

Proline was extracted and its concentration determined by the method of Bates et al. [22]. Leaf segments were homogenized with $3 \%$ sulfosalicylic acid and the homogenate was centrifuged at $3000 \times g$ for $20 \mathrm{~min}$. The supernatant was treated with acetic acid and acid ninhydrin, boiled for $1 \mathrm{~h}$, and then absorbance at $520 \mathrm{~nm}$ was determined. Contents of proline are expressed as $\mu \mathrm{mol} \mathrm{g}^{-1}$ FW. For determination of glutamic acid, glutamine, arginine, ornithine, $\gamma$-aminobutyric acid (GABA), and total amino acids, leaf samples were extracted with $2 \%$ sulfosalicylic acid and the homogenate was centrifuged at $15000 \times g$ for 20 min. The supernatant was used directly for amino acid analysis. Amino acid analysis was carried out by an amino acid analyzer (Beckman 6300, CA, USA). Proline content reported in Figs. 3 and 5 was also determined by the amino acid analyzer. For protein determination, leaf segments were homogenized in $50 \mathrm{mM}$ sodium phosphate buffer ( $\mathrm{pH}$ 6.8). The extracts were centrifuged at $17600 \times g$ for $20 \mathrm{~min}$, and the supernatants were used for determination of protein by the method of Bradford [23]. Chlorophyll was determined according to Wintermans and De Mots [24] after extraction in $96 \%(\mathrm{v} / \mathrm{v})$ ethanol.

\section{3. $R W C$ and $\mathrm{Cu}$ measurements}

RWC, defined as water content of leaf tissue as a percentage that of the fully turgid tissue, was determined by the method of Weatherly [25]. For determination of $\mathrm{Cu}$, leaf segments were dried at $65^{\circ} \mathrm{C}$ for $48 \mathrm{~h}$. Dried material was ashed at $550^{\circ} \mathrm{C}$ for $20 \mathrm{~h}$. Ash residue was incubated with $31 \%$ $\mathrm{HNO}_{3}$ and $17.5 \% \mathrm{H}_{2} \mathrm{O}_{2}$ at $72{ }^{\circ} \mathrm{C}$ for $2 \mathrm{~h}$, and dissolved in a mixture of $70 \% \mathrm{HNO}_{3}$ and $60 \%$ $\mathrm{HClO}_{4}$ (9:1). $\mathrm{Cu}$ was then quantified using an atomic absorption spectrophotometer (Model AA6800, Shimadzu, Kyoto).

\subsection{ABA assay}

For extraction of abscisic acid (ABA), leaf samples were homogenized with a mortar and pestle in extraction solution ( $80 \%$ methanol containing $2 \%$ galacial acetic acid). To remove plant pigments and other non-polar compounds which could in- 
terfere in the immunoassay, extracts were first passed through polyvinylprrrolidone column and C18 cartridges. The elutes were concentrated to dryness by vaccum-evaporation and resuspended in Tris-buffered saline before enzyme-linked immunosorbent assay (ELISA). ABA was quantitated by ELISA [26]. ABA immunoassay detection kit (PGR-1) was purchased from Sigma Chemical Co. (St Louis, MO, USA), is specific for $(+)$ ABA.

\subsection{Enzyme assay}

For enzyme extraction, leaf samples were homogenized in prechilled mortar and pestle with extraction medium at $4^{\circ} \mathrm{C}$. The extraction medium contained $100 \mathrm{mM}$ potassium phosphate buffer (pH 7.4), $1 \mathrm{mM}$ pyridoxal 5-phosphate, $1 \mathrm{mM}$ EDTA, $10 \quad \mathrm{mM}$ mercaptoethanol, $1 \%$ polyvinylpyrrolidone, $5 \mathrm{mM} \mathrm{MgCl}_{2}$, and $0.6 \mathrm{M}$ $\mathrm{KCl}$. The homogenate was centrifuged at $12000 \times g$ for $20 \mathrm{~min}$ at $4^{\circ} \mathrm{C}$. The resulting clean supernatant fractions were desalted by Sephadex G-25 column before the enzyme assay.

P5CR was assayed by a NADH dependent $\mathrm{P} 5 \mathrm{CR}$ reaction [27]. The assay mixture contained $0.4 \mathrm{mM}$ NADH, $1.5 \mathrm{mM}$ P5C, $50 \mathrm{mM}$ potassium phosphate buffer, $0.8 \mathrm{mM}$ dithiothreitol, and the enzyme extract. The reaction was started by the addition of $\mathrm{P} 5 \mathrm{C}$ and the decrease in absorbance was followed at $340 \mathrm{~nm}$. One unit of P5CR was defined as 1 nmol NADH oxidized $\mathrm{h}^{-1}$. OAT activity was assayed according to Vogel and Kopac [28]. In the final volume of $1 \mathrm{ml}$, the reaction medium contained: $50 \mathrm{mM}$ ornithine, $20 \mathrm{mM} \alpha$ ketoglutarate, $1 \mathrm{mM}$ pridoxal 5-phosphate, 100 $\mathrm{mM}$ potassium phosphate buffer, and the enzyme extract, the final $\mathrm{pH}$ was 8.0. The reaction medium was incubated at $37^{\circ} \mathrm{C}$ for $30 \mathrm{~min}$. The reaction was stopped by adding $0.5 \mathrm{ml}$ trichloroacetic acid $(10 \%)$ and the color was developed by incubatng the reaction mixture with $0.5 \mathrm{ml} o$-aminobenzaldehyde $(0.5 \%)$ in ethanol $(95 \%)$ for $1 \mathrm{~h}$. After centrifugation at $12000 \times g$ for $10 \mathrm{~min}$, the clear supernatant fraction was taken to measure the absorbance at $440 \mathrm{~nm}$. Enzyme activity was calculated using the extinction coefficient $\left(2.68 \mathrm{mM}^{-1}\right.$ $\mathrm{cm}^{-1}$ at $440 \mathrm{~nm}$ ). The activity was expressed in units, where one unit of OAT was defined as 1 nmol P5C produced $\mathrm{h}^{-1}$. PDH was assayed by following the NAD reduction at $340 \mathrm{~nm}$ in a 100
$\mathrm{mM} \mathrm{Na} \mathrm{CO}_{3}-\mathrm{NaHCO}_{3}$ buffer ( $\mathrm{pH}$ 10.3) containing $50 \mathrm{mM}$ proline, $0.4 \mathrm{mM} \mathrm{NAD}$, and the enzyme extract [29]. One unit of PDH was defined as $1 \mathrm{nmol}$ NAD reduced $\mathrm{h}^{-1}$. P5CDH was assayed by monitoring the production of $\mathrm{NADH}$ at 340 $\mathrm{nm}$. The reaction mixture contained $50 \mathrm{mM}$ potassium phosphate buffer ( $\mathrm{pH} 8.0), 4 \mathrm{mM}$ NAD, 1.5 $\mathrm{mM}$ P5C, and the enzyme extract [30]. One unit of $\mathrm{P} 5 \mathrm{CDH}$ was defined as 1 nmol NAD reduced $\mathrm{h}^{-1}$.

\subsection{Determination of proline utilization}

For proline utilization, detached rice leaves were pretreated with $50 \mathrm{mM}$ ornithine for $3 \mathrm{~h}$ (since addition of ornithine has been observed to be more effective than that of glutamic acid or arginine in increasing proline content in rice leaves [31]) to increase the endogenous proline content and then transferred to distilled water and $10 \mathrm{mM}$ $\mathrm{CuSO}_{4}$ for $12 \mathrm{~h}$ in the light. Proline content was then determined. The decline in proline content will be considered as that proline is utilized [31].

\section{Results}

Proline content in detached rice leaves increased with the increase of $\mathrm{CuSO}_{4}$ concentration (Fig. 1). Proline content increased about 2.5-fold in detached leaves treated with $10 \mathrm{mM} \mathrm{CuSO}_{4}$ for $24 \mathrm{~h}$ under both light and dark conditions. It is obvious

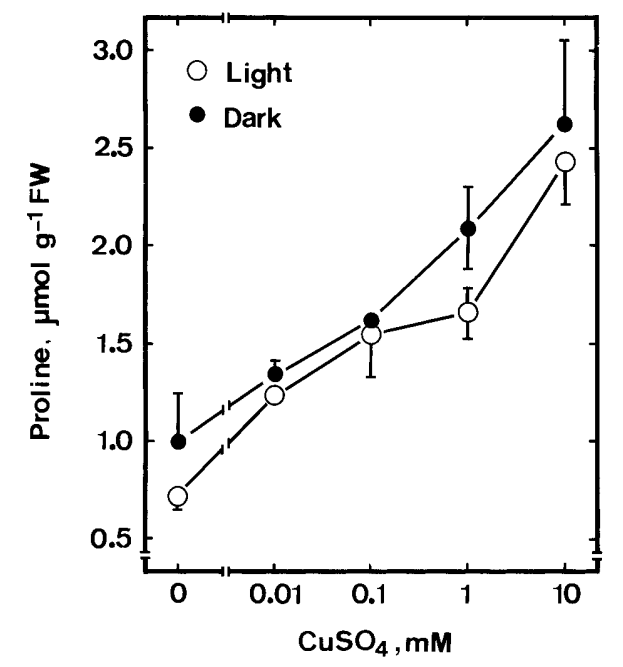

Fig. 1. Effect of $\mathrm{CuSO}_{4}$ on proline content in detached rice leaves under light and dark conditions. Detached rice leaves were incubated in solutions containing $0-10 \mathrm{mM} \mathrm{CuSO}_{4}$. Proline was determined $24 \mathrm{~h}$ after treatment in the dark or in the light. Vertical bars represent standard errors $(n=4)$. 


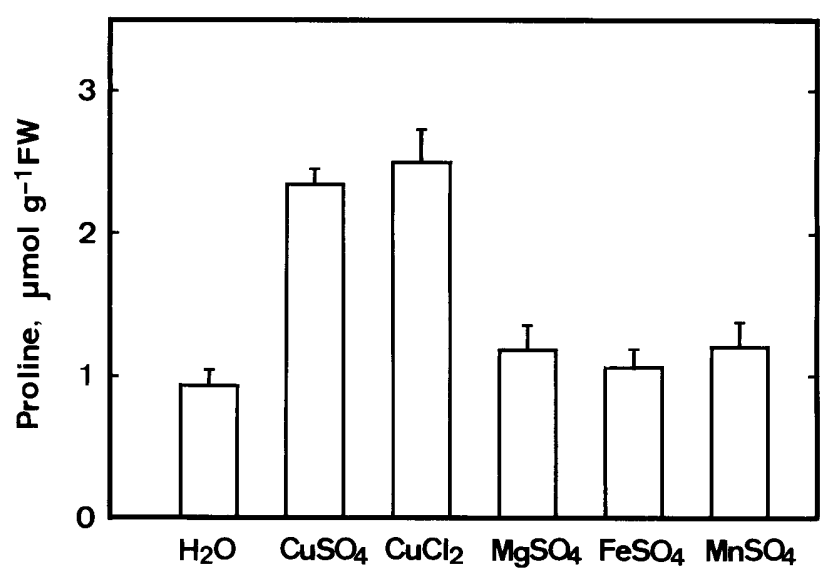

Treatment

Fig. 2. Effect of various divalent metals on proline contents in detached rice leaves. Proline was determined $24 \mathrm{~h}$ after treatment of metals $(10 \mathrm{mM})$ in the light. Vertical bars represent standard errors $(n=4)$.

that $\mathrm{CuSO}_{4}$ in the light and $\mathrm{CuSO}_{4}$ in the dark were equally effective in inducing proline accumulation in detached rice leaves.

Fig. 2 shows the effect of various divalent metals on the proline content in detached rice leaves. It is clear that sulfate salt of $\mathrm{Mg}, \mathrm{Fe}$ and $\mathrm{Mn}$ at $10 \mathrm{mM}$ did not affect proline content in detached rice leaves. Fig. 2 also shows that $\mathrm{CuSO}_{4}$ and $\mathrm{CuCl}_{2}$ were equally effective in inducing proline accumulation. Chloride salt of $\mathrm{Cd}, \mathrm{Co}, \mathrm{Zn}, \mathrm{Ni}$ and $\mathrm{Al}$ was also effective in increasing proline content in detached rice leaves (data not shown).

Proline content in control leaves remained almost unchanged during the first $12 \mathrm{~h}$ of incubation in the light (Fig. 3). It is clear from Fig. 3 that accumulation of proline induced by $\mathrm{CuSO}_{4}$ was evident at $4 \mathrm{~h}$ after treatment.

To be sure that the described proline accumulation was related to an increase in the leaf $\mathrm{Cu}$ content, $\mathrm{Cu}$ concentrations were determined in detached rice leaves treated with either water or 10 $\mathrm{mM} \mathrm{CuSO}_{4}$ (Fig. 4). Cu content in control leaves remained unchanged during the first $12 \mathrm{~h}$ in the light. However, $\mathrm{Cu}$ content in $\mathrm{CuSO}_{4}$-treated detached rice leaves increased with increasing duration of incubation. It is obvious that the increase in $\mathrm{Cu}$ content in $\mathrm{CuSO}_{4}$-treated detached rice leaves was evident $4 \mathrm{~h}$ after treatment. The effect of $\mathrm{CuSO}_{4}$ on RWC and ABA content in detached rice leaves is shown in Fig. 4. No differences in RWC were observed between $\mathrm{Cu}$-treated leaves and control leaves. Unexpectedly, ABA content in $\mathrm{CuSO}_{4}$-treated rice leaves was observed to be much higher than that in water-treated controls throughout the entire duration of incubation.

The results of Fig. 5 show that protein and chlorophyll a contents decreased and total amino acids increased with increasing duration of $\mathrm{CuSO}_{4}$ stress. Endogenous arginine, glutamine and GABA contents in detached rice leaves treated with $\mathrm{CuSO}_{4}$ were higher than those treated with water (Fig. 3). However, the content of glutamic acid in $\mathrm{CuSO}_{4}$-treated detached rice leaves was much lower than that in water-treated detached rice leaves in $12 \mathrm{~h}$ of incubation (Fig. 3). There was no clear differences in ornithine content between $\mathrm{CuSO}_{4}{ }^{-}$and water-treated detached rice leaves in $12 \mathrm{~h}$ of incubation (Fig. 3).

To determine the role of biosynthetic pathways for proline accumulation caused by $\mathrm{CuSO}_{4}$, the

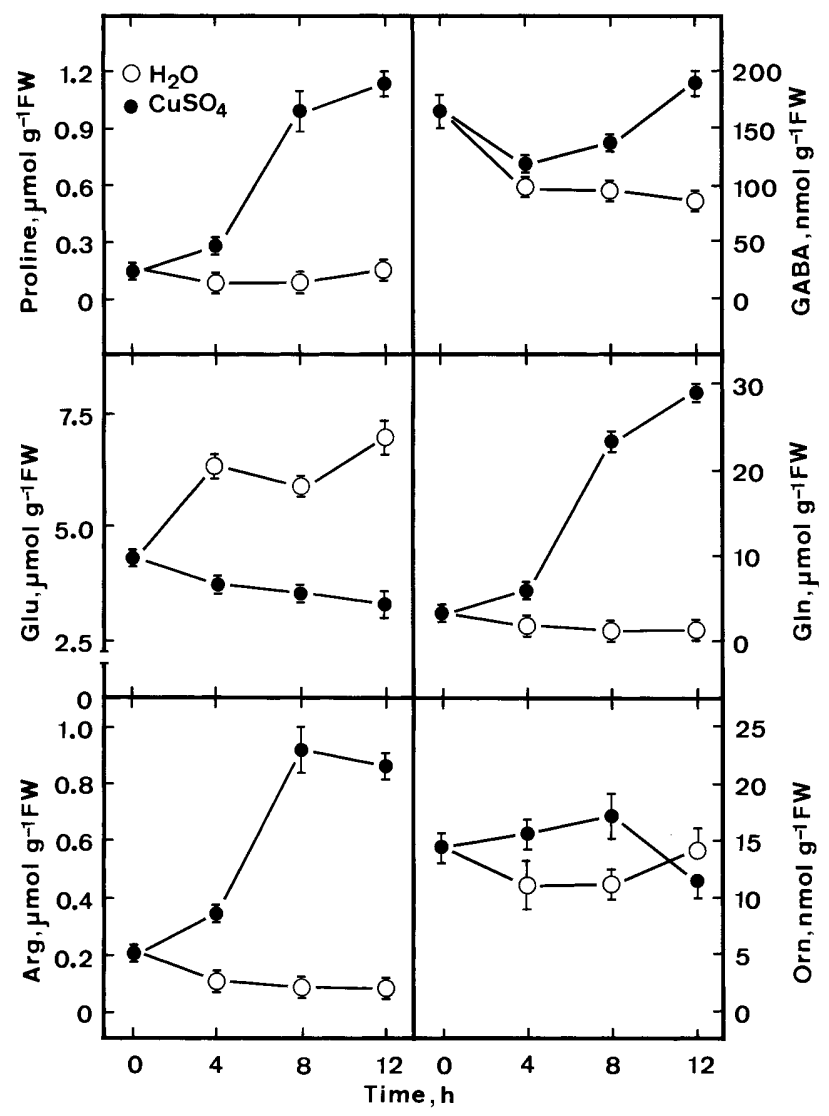

Fig. 3. Time course of the $\mathrm{CuSO}_{4}$ effect on proline, glutamic acid (Glu), glutamine (Gln), $\gamma$-aminobutyric acid (GABA), arginine (Arg) and ornithine (Orn) contents in detached rice leaves. Detached rice leaves were incubated in water or 10 $\mathrm{mM} \mathrm{CuSO}_{4}$ in the light. Amino acids were determined by amino acid analyzer. Vertical bars represent standard errors $(n=4)$. 


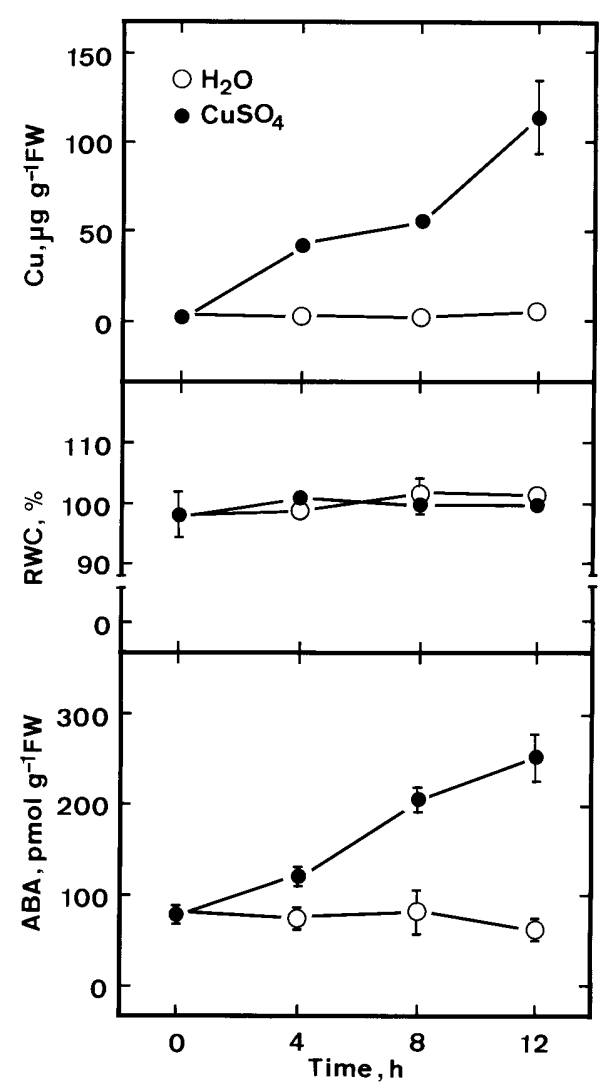

Fig. 4. Time course of the $\mathrm{CuSO}_{4}$ effect on $\mathrm{Cu}$ content, relative water content (RWC), and $\mathrm{ABA}$ content in detached rice leaves. Detached rice leaves were incubated in water or 10 $\mathrm{mM} \mathrm{CuSO}_{4}$ in the light. Vertical bars represent standard errors $(n=4)$.

effect of $\mathrm{CuSO}_{4}$ on OAT and P5CR activities was examined. The results are shown in Fig. 6. It is clear that OAT activity increased with the increasing duration of $\mathrm{CuSO}_{4}$ similar to that observed for proline accumulation. Fig. 6 also shows that P5CR activity in $\mathrm{CuSO}_{4}$-treated detached rice leaves was higher than that in water-treated detached rice leaves. In contrast, no clear differences between $\mathrm{CuSO}_{4}$-stressed and non-stressed rice leaves were observed for PDH and P5CDH activities (Fig. 6). Recently, we demonstrated that proline in detached rice leaves exposed to water stress is less utilized than in water control [32]. It is possible that less utilization may also contribute to the accumulation of proline in detached rice leaves exposed to excess $\mathrm{CuSO}_{4}$. However, the results presented in Table 1 show that proline in $\mathrm{CuSO}_{4}$ treated rice leaves was utilized as effective as in water-treated rice leaves.

\section{Discussion}

The present investigation shows that excess $\mathrm{CuSO}_{4}$ induces the accumulation of proline in detached rice leaves. This result is in agreement with those of other investigators using different plants as experimental materials [7-12]. The fact that $\mathrm{CuSO}_{4}$ and $\mathrm{CuCl}_{2}$ were equally effective in

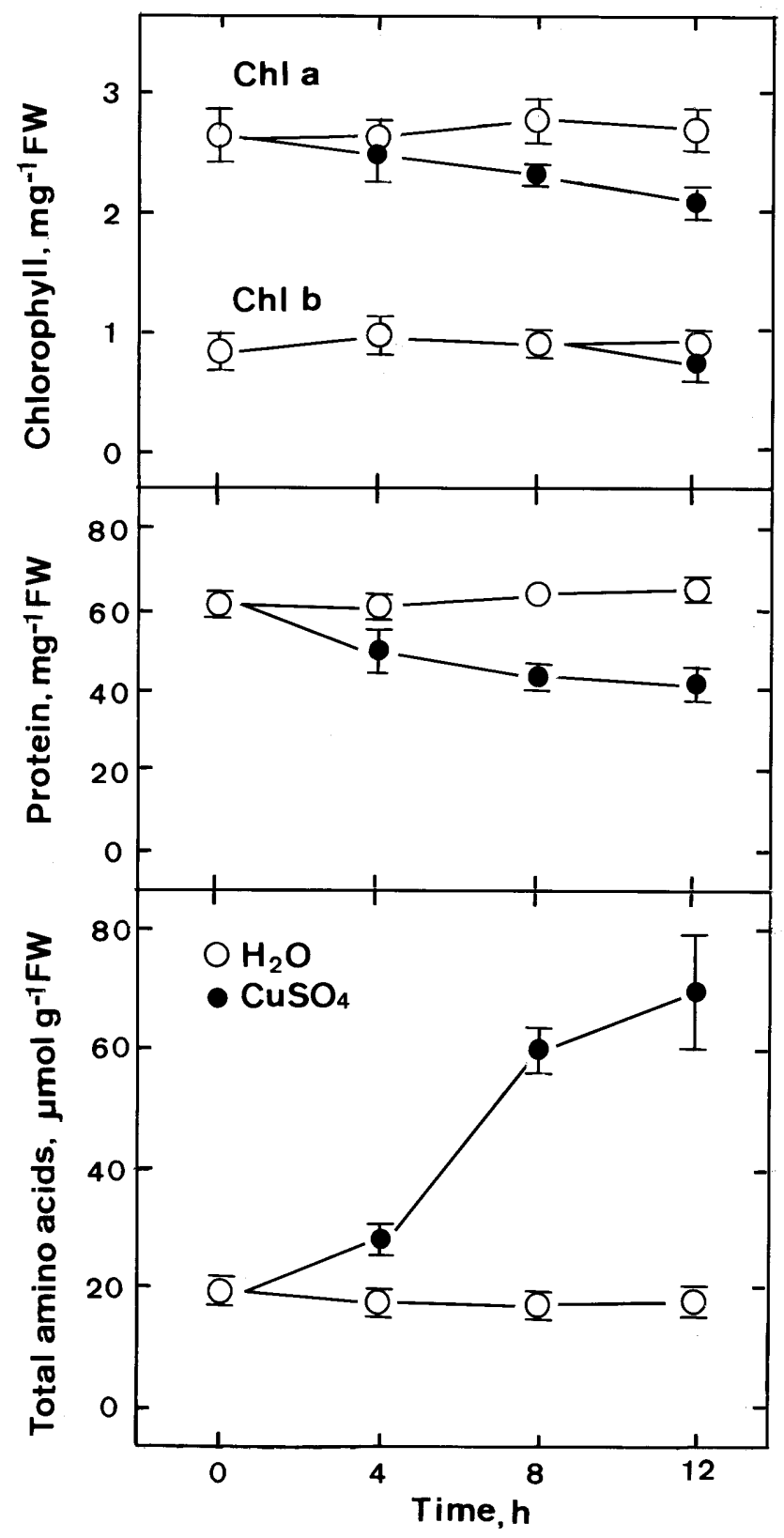

Fig. 5. Time course of the $\mathrm{CuSO}_{4}$ effect on the contents of chlorophyll, protein and total amino acids in detached rice leaves. Detached rice leaves were incubated in water or 10 $\mathrm{mM} \mathrm{CuSO}_{4}$ in the light. Total amino acid contents were determined by amino acid analyzer. Vertical bars represent standard errors $(n=4)$. 


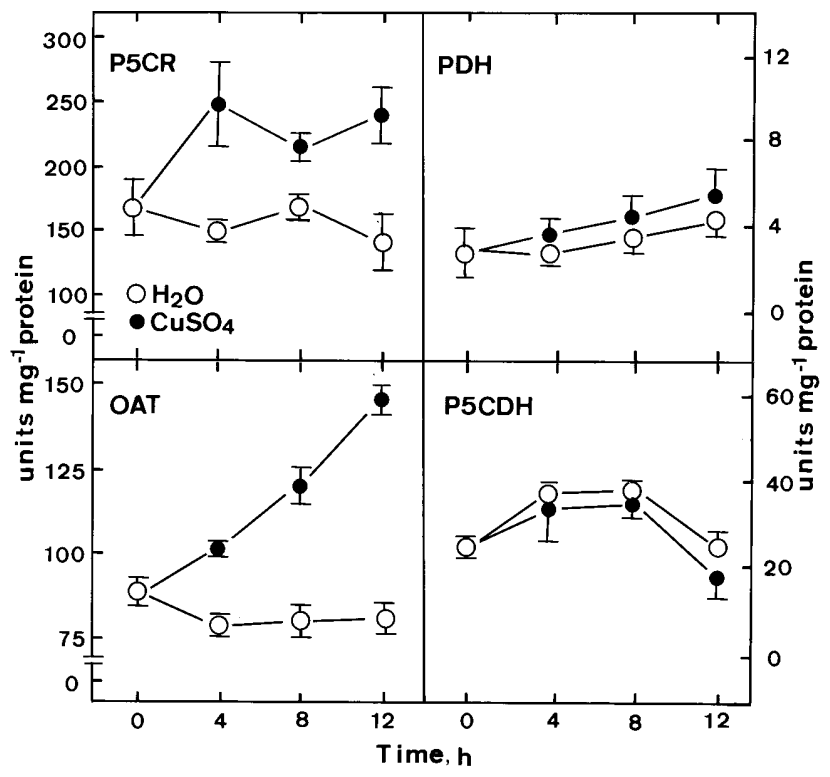

Fig. 6. Time course of the $\mathrm{CuSO}_{4}$ effect on the activities of $\mathrm{P} 5 \mathrm{CR}, \mathrm{OAT}, \mathrm{PDH}$ and $\mathrm{P} 5 \mathrm{CDH}$ in detached rice leaves. Detached rice leaves were incubated in water or $10 \mathrm{mM}$ $\mathrm{CuSO}_{4}$ in the light. Vertical bars represent standard errors $(n=4)$.

inducing proline accumulation indicates that proline accumulation induced by $\mathrm{Cu}$ is rather than by $\mathrm{SO}_{4}^{2-}$ or $\mathrm{Cl}^{-}$(Fig. 2). Our results also show that proline content in $\mathrm{CuSO}_{4}$-treated detached rice leaves increased progressively with an increase in duration of the incubation time (Fig. 3) as well as in a concentration-dependent manner (Fig. 1).

There are many reports indicate that light promotes stress- and Cd-induced proline accumulation in plants [33-37]. Recently, Wu et al. [10] also demonstrated that $\mathrm{Cu}$ - or Cd-treated Chlorella sp. accumulated more proline under light condition than dark condition. However, our results indicate that there is no requirement for light in the accumulation of proline as a response to excess $\mathrm{Cu}$ (Fig. 1). We do not have a good explanation for

\section{Table 1}

Proline content in ornithine-pretreated detached rice leaves incubated in water and $\mathrm{CuSO}_{4}{ }^{\mathrm{a}}$

\begin{tabular}{lr}
\hline Treatment & Proline, $\mu$ \\
\hline Ornithine, 3 h & $25.4 \pm 0.5$ \\
Ornithine, 3 h $\rightarrow \mathrm{H}_{2} \mathrm{O}, 12 \mathrm{~h}$ & $7.1 \pm 0.9$ \\
Ornithine, 3 h $\rightarrow \mathrm{CuSO}_{4}, 12 \mathrm{~h}$ & $7.9 \pm 0.7$
\end{tabular}

${ }^{\text {a }}$ Detached rice leaves were pretreated with $50 \mathrm{mM}$ ornithine for $3 \mathrm{~h}$ in the light and then incubated in water or $\mathrm{CuSO}_{4}(10 \mathrm{mM})$ for $12 \mathrm{~h}$ in the light. Means \pm S.E. $(n=4)$. such a difference except that it is possible that plant species (O. sativa) we used in our experiment may somewhat have contributed to different results. We also observed that promotion of senescence of detached rice leaves caused by $\mathrm{CuSO}_{4}$ was not light dependent and that $\mathrm{CuSO}_{4}$-promoted senescence of detached rice leaves is linked to lipid peroxidation [38].

Exposure to heavy metals including $\mathrm{Cu}$ is known to deteriorate the plant water balance [6,39-41]. It has been suggested that proline accumulation induced by metals such as $\mathrm{Cu}, \mathrm{Cd}$ and $\mathrm{Zn}$ depends on the development of a metal-induced water stress in leaves $[9,40]$. Since $\mathrm{Cu}$ had no effect on RWC of detached rice leaves (Fig. 4), it is unlikely that $\mathrm{Cu}$-induced proline accumulation is attributed to the development of water stress. Kastori et al. [41] also observed that proline accumulation in $\mathrm{Cu}$-exposed leaf discs and argued that this was due to $\mathrm{Cu}$ uptake per se, rather than to water stress.

The decrease in protein content was faster in $\mathrm{CuSO}_{4}$-stressed detached rice leaves than watertreated detached rice leaves (Fig. 5). Therefore, protein degradation might contribute to the $\mathrm{CuSO}_{4}$-induced proline accumulation in detached rice leaves. This conclusion is supported further by the observation that total amino acids are higher in detached rice leaves exposed to $\mathrm{CuSO}_{4}$ than in those treated with water (Fig. 5).

Proline is known to be synthesized from glutamic acid via P5C by two enzymes, P5C synthetase and P5CR [3,4]. In the present study, P5CR was found to be higher in $\mathrm{CuSO}_{4}$-treated detached rice leaves than in water-treated detached rice leaves (Fig. 6), suggesting that glutamic acid is converted to proline in rice leaves exposed to excess $\mathrm{CuSO}_{4}$. It was further supported by the decreased or low content of glutamic acid in $\mathrm{CuSO}_{4}$-stressed detached rice leaves (Fig. 3). Since GABA contents in $\mathrm{CuSO}_{4}$-treated detached rice leaves was observed to be higher than those in water-treated detached rice leaves, therefore the decreased content of glutamic acid also resulted from glutamic acid being metabolized to GABA [42]. The increase in glutamine content and the decrease in glutamic acid in $\mathrm{CuSO}_{4}$-treated detached rice leaves also suggest that $\mathrm{CuSO}_{4}$ inhibits the conversion of glutamine to glutamic acid, a step catalyzed by glutamic acid synthase [42]. $\mathrm{CuSO}_{4}$ could also have an effect on the bifunc- 
tional enzyme P5C synthetase involved in the synthesis of P5C from glutamic acid [4]. However, for unknown reasons, we were unable to detect any P5C synthetase activity in crude extracts. Therefore, this enzyme was not considered in the present work.

OAT catalyzes the first step in the pathway of conversion of ornithine to proline [4]. In the present investigation, OAT activity was found to increase significantly in detached rice leaves exposed to excess $\mathrm{Cu}$ (Fig. 6). The increase in OAT activity may have, to some extent, contributed to the elevated content of proline. Increase in OAT activity along with an increase in the content of proline has also reported in wheat under cold stress [13], and in Brassica juncea under salt stress [28]. Both ornithine and arginine can contribute to proline biosynthesis. It is interesting to note that the increase in arginine, but not ornithine content was found to be associated with the increase in proline content in $\mathrm{CuSO}_{4}$-stressed detached rice leaves (Fig. 3).

The enzymes, $\mathrm{PDH}$ and $\mathrm{P} 5 \mathrm{CDH}$, are reported to catalyze proline oxidation $[3,4]$. In the present investigation, no effect of $\mathrm{CuSO}_{4}$ has been observed on PDH and P5CDH activities in detached rice leaves (Fig. 6). These results suggest that proline oxidation (or degradation) contribute little, if any, to proline accumulation in detached rice leaves under $\mathrm{CuSO}_{4}$ stress condition.

Of particular interest is the finding that ABA accumulates in detached rice leaves exposed to excess $\mathrm{Cu}$ (Fig. 4). Since $\mathrm{CuSO}_{4}$ had no effect on RWC of detached rice leaves (Fig. 4), the accumulation of $\mathrm{ABA}$ caused by $\mathrm{CuSO}_{4}$ is unlikely due to the development of water stress. Proline accumulation in detached rice leaves can be induced by ABA treatment [32]. It is not known whether $\mathrm{Cu}$-induced proline accumulation in detached rice leaves is mediated through accumulation of ABA. Previously, we have demonstrated that ABA-induced proline accumulation was not due to less utilization of proline in detached rice leaves [32]. In the present investigation, we also observed that proline accumulation in detached rice leaves exposed to $\mathrm{CuSO}_{4}$ was not caused by less utilization of proline (Table 1). However, further investigation is required to establish the cause and effect link between ABA and proline accumulations in detached rice leaves exposed to $\mathrm{CuSO}_{4}$ stress.

\section{Acknowledgements}

This work was supported by the National Science Council of the Republic of China (NSC 88-2313-B-002-066).

\section{References}

[1] J.S. Boyer, Plant productivity and environment, Science 218 (1982) 443-448.

[2] D. Aspinall, L.G. Paleg, Proline accumulation: physiological aspects, in: L.G. Paleg, D. Aspinall (Eds.), The Physiology and Biochemistry of Drought Resistance in Plants, Academic Press, Sydney, 1981, pp. 205-241.

[3] Y. Yoshiba, T. Kiyosue, K. Nakashima, K. YamaguchiShinozaki, K. Shinozaki, Regulation of levels of proline as an osmolyte in plants under water stress, Plant Cell Physiol. 38 (1997) 1095-1102.

[4] P.D. Hare, W.A. Cress, J. van Staden, Proline synthesis and degradation: a model system for elucidating stressrelated signal transduction, J. Exp. Bot. 50 (1999) 413434.

[5] J.C. Fernandes, F.S. Henriques, Biochemical, physiological and structural effect of excess copper in plants, Bot. Rev. 57 (1991) 246-273.

[6] J. Barcelo, V. Poschenrieder, Plant water relations as affected by heavy metal stress: a review, J. Plant Nutr. 13 (1990) 1-37.

[7] R. Bassi, S.S. Sharma, Proline accumulation in wheat seedlings exposed to zinc and copper, Phytochemistry 33 (1993) 1339-1342.

[8] R. Bassi, S.S. Sharma, Changes in proline content accompanying the uptake of zinc and copper by Lemna minor, Ann. Bot 72 (1993) 151-154.

[9] H. Schat, S.S. Sharma, R. Vooijs, Heavy metal-induced accumulation of free proline in a metal-tolerant and a nontolerant ecotype of Silene vulgaris, Physiol. Plant. 101 (1997) 477-482.

[10] J.-T. Wu, S.-C. Chang, K.-S. Chen, Enhancement of intracellular proline level in cells of Anacystis nidulans (Cyanobacteria) exposed to deleterious concentration of copper, J. Phycol. 31 (1995) 376-379.

[11] J.-T. Wu, M.-T. Hsieh, L.-C. Know, Role of proline accumulation in response to toxic copper in Chlorella sp. (chlorophyceae) cells, J. Phycol. 34 (1998) 113-117.

[12] J.-T. Wu, S.-J. Chang, T.-L. Chou, Intracellular proline accumulation in some algae exposed to copper and cadmium, Bot. Bull. Acad. Sin. 36 (1995) 89-93.

[13] C. Charest, C.T. Phan, Cold acclimation of wheat (Triticum aestvum): properties of enzymes involved in proline metabolism, Physiol. Plant. 80 (1990) 159-168.

[14] D.H. Brown, L. Fowden, Metabolism of $\delta$-acetylornithine in two Leguminous species, Phytochemistry 5 (1966) 887-892.

[15] H.-H. Chiang, A.M. Dandekar, Regulation of proline accumulation in Arabidopsis thaliana (L.) Heynh during development and in response to desication, Plant Cell Environ. 18 (1995) 1280-1290. 
[16] R.G. Coleman, M.P. Hegarty, Metabolism of D, L-ornithine- $2{ }^{14} \mathrm{C}$ in normal and potassium-deficient barley, Nature 179 (1957) 376-377.

[17] A.J. Delauney, C.A.A. Hu, P.B. Kavi Kishor, D.P.S. Verma, Cloning of ornithine $\delta$-aminotransferase cDNA from Vigna aconitifolia by trans-complementation in Escherichia coli and regulation of proline biosynthesis, J. Biol. Chem. 268 (1993) 18673-18678.

[18] N.H.C.J. Roosens, T.T. Thu, H.M. Iskandar, M. Jacobs, Isolation of the ornithine- $\delta$-aminotransferase cDNA and effect of salt stress on its expression in Arabidopsis thaliana, Plant Physiol. 117 (1998) 263-271.

[19] E.M. Lingnowski, W.E. Splittstoesser, The change in arginine levels and the metabolism of urea and ornithine in Cucubita moschatta seedlings, Physiol. Plant. 25 (1971) 225-229.

[20] J.-N. Lin, J.-W. Wang, C.H. Kao, Effect of abscisic acid and water stress on the senescence of detached rice leaves, Biol. Plant. 42 (1999) 313-316.

[21] C.M. Johnson, P.R. Stout, T.C. Broyer, A.B. Carlton, Comparative choline requirements of different plant species, Plant Soil 8 (1957) 337-353.

[22] L.S. Bates, S.P. Waldren, I.D. Teare, Rapid determination of free proline for water-stress studies, Plant Soil 39 (1973) 205-207.

[23] M.M. Bradford, A rapid and sensitive method for the quantitation of microgram quantities for protein utilizing the principles of protein-dye binding, Anal. Biochem. 72 (1976) 248-254.

[24] J.F.G.M. Wintermans, A. De Mots, Spectrophotometric characteristics of chlorophyll $a$ and $b$ and their pheophytins in ethanol, Biochem. Biophys. Acta 109 (1965) 448-453.

[25] P.F. Weatherly, Studies in the water relation of cotton plant. I. The field measurement of water deficits in the leaves, New Phytol. 49 (1950) 81-97.

[26] M. Walker-Simmons, ABA levels and sensitivity in developing wheat embryos of sprouting resistant and susceptible cultivars, Plant Physiol. 84 (1987) 61-66.

[27] S. Madan, H.S. Nainawatee, R.K. Jain, J.B. Chowdhury, Proline and proline metabolising enzymes in invitro selected $\mathrm{NaCl}$-tolerant Brassia juncea $\mathrm{L}$. under salt stress, Ann. Tot. 76 (1995) 51-57.

[28] R.H. Vogel, M.J. Kopac, Some properties of ornithine$\delta$-transaminase from Neurospore, Biochem. Biophys. Acta 37 (1960) 539-540.

[29] A.B. Rena, W.E. Splittstoesser, Proline dehydrogenase and pyrroline-5-carboxylate reductase from pumpkin cotyledons, Phytochemistry 14 (1975) 657-661.
[30] S.F. Boggess, L.G. Paleg, D. Aspinall, $\Delta^{1}$-Pyrroline-5carboxylic acid dehydrogenase in barley, a proline-accumulating species, Plant Physiol. 56 (1975) 259-262.

[31] C.-W. Yang, C.-C. Lin, C.H. Kao, Endogenous ornithine and arginine contents and dark-induced proline accumulation in detached rice leaves, J. Plant Physiol. 155 (1999) 665-668.

[32] C.-W. Yang, J.W. Wang, C.H. Kao, The relation between accumulation of abscisic acid and proline in detached rice leaves, Biol. Plant. 43 (2000) 301-314

[33] S. Arora, P. Pardha Saradhi, Light-induced enhancement in proline levels in Vigna radiata exposed to environmental stress, Aust. J. Plant Physiol. 22 (1995) 383-386.

[34] A.D. Hanson, R.E. Tully, Light stimulation of proline synthesis in water-stressed barley leaves, Planta 145 (1979) 45-51.

[35] P.S. Joyce, L.G. Paleg, D. Aspinall, The requirement for low-intensity light in the accumulation of proline as a response to water deficit, J. Exp. Bot. 35 (1984) 209218.

[36] C.R. Stewart, Role of carbohydrate in proline accumulation in wilted barley leaves, Plant Physiol. 61 (1978) $775-778$.

[37] J.H. Venekamp, J.E.M. Lampe, J.T.M. Koot, Organic acids as sources of drought induced proline synthesis in field bean plants, Vicia faba L, J. Plant Physiol. 133 (1989) 654-659.

[38] L.-M. Chen, C.H. Kao, Effect of excess copper on rice leaves: evidence for involvement of lipid peroxidation, Bot. Bull. Acad. Sin. 40 (1999) 283-287.

[39] J.C. Barcelo, Poschenrieder, I. Andreu, B. Gunse, Cadmium induced decrease of water stress resistance in bush bean plants (Phaseolus vulgaris L. cv. Conender). I. Effect on water potential, relative water content and cell wall elasticity, J. Plant Physiol. 125 (1986) $17-25$.

[40] G. Costa, J.-L. Morel, Water relations, gas exchange and amino acid content in Cd-treated lettuce, Plant Physiol. Biochem. 32 (1994) 561-570.

[41] R. Kastori, M. Petrovic, N. Petrovic, Effect of excess lead, cadmium, copper, and zinc of water relations in sunflower, J. Plant Nutr. 15 (1992) 2427-2439.

[42] A.J. Ireland, P.J. Lea, The enzymes of glutamine, glutamate, asparagine, and aspartate metabolism, in: B.K. Singh (Ed.), Plant Amino Acids, Mercel Dekker, New York, 1999, pp. 49-109. 